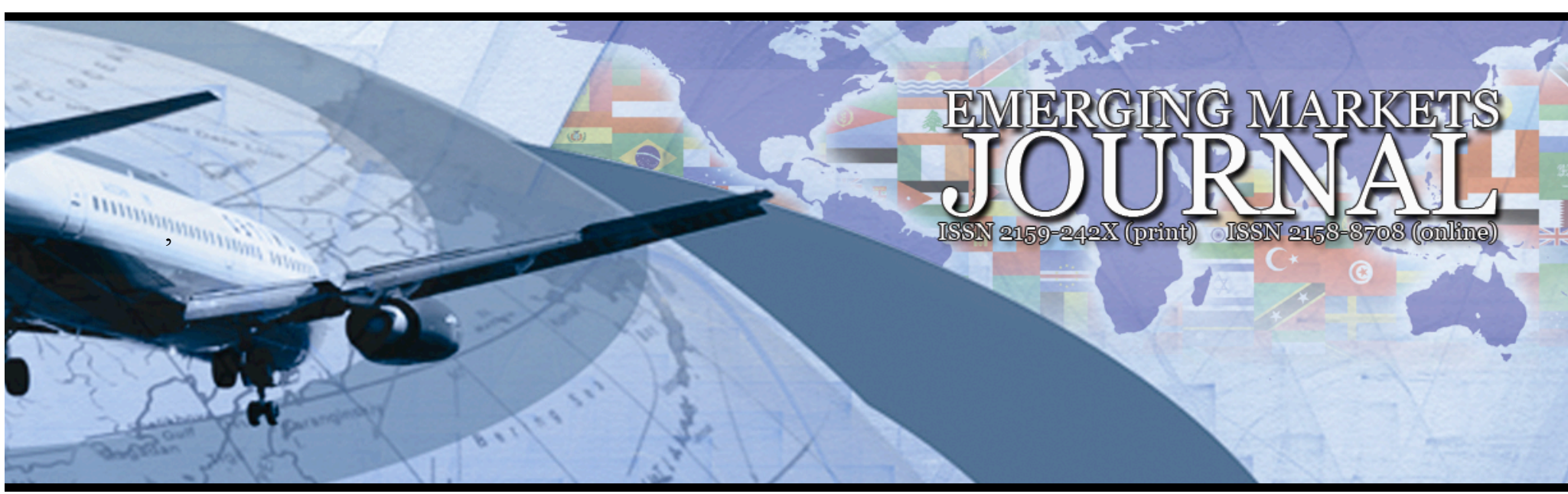

\title{
HUMAN CAPITAL HETEROGENEITY AND ORGANZATIONAL PERFORMANCE ANALYSIS: AN EMPIRICAL STUDY ABOUT INTERNATIONAL HOTEL CHAINS IN TURKEY
}

\author{
Murat Kasimoglu \\ Canakkale Onsekiz Mart University | e-mail: mkasimoglu@yahoo.co.uk
}

Ramazan Aktaş

TOBB University

Volume 2 (2011)

\author{
Murat Kasimoğlu \\ Canakkale Onsekiz Mart University
}

\author{
Ali Halici
}

Baskent University

\author{
Ahu Genis Gruber \\ TOBB University
}

\section{Abstract}

Today, workforce diversity is not only a legal requirement for organizations, but it is also a must to survive in a highly competitive business environment. The prime motive for this study is to investigate the relationship between workforce diversity and perception of discrimination. The basic hypothesis of the study is that as the workforce diversity increases, the perception of discrimination decreases. In order to test the hypothesis, a survey is carried out international hotel chains in Istanbul. There are 19 international hotel chains in Turkey. In this study research is designed to understand human capital heterogeneity pattern of international chains of hotel industry and how this contribute organizational culture strategically that help to manage organizational performance much more efficiently with cross sectional data. Globalization of markets, changing demographics in the labor market, new business strategies requiring team work and the shift from a manufacturing to a service economy are the prime reasons for human capital heterogeneity $(\mathrm{HCH}) . \mathrm{HCH}$ improves the organizational capabilities in terms of flexibility, creativity, problem solving and competitive advantage. Especially in the service sector, in order to gain competitive advantage, organizations need a diverse workforce for both understanding the diverse needs of customers and answering to these needs in a prompt and proper way.

Keywords: human capital, organizational performance, hotel chain

\section{(cc) BY-NC-ND}

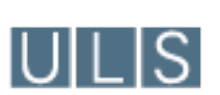

This work is licensed under a Creative Commons Attribution-Noncommercial-No Derivative Works 3.0 United States License.

This journal is published by the University Library System of the University of Pittsburgh as part 
Human Capital Heterogeneity And Organzational Performance Analysis: An Empirical Study About International Hotel Chains In Turkey

Murat Kasimoglu

Ali Halici

Ramazan Aktaş

Murat Kasimoğlu

Ahu Genis Gruber

\section{Introduction}

Although there are various classifications of discrimination types in the literature, two of the most widely stated ones are disparate treatment and disparate impact. Disparate treatment occurs when individuals in similar situations are intentionally treated differently based on such factors as race, religious belief, sex, age, national origin, disability status. Disparate impact occurs as a result of employment processes or decisions that result in discrimination, although there is no such discriminatory intention.

Discriminatory practices towards workforce result basically from prejudice against individuals or certain groups (women, black people, the disabled etc.) There are negative consequences of discriminatory practices for the organizations such as high turnover rates, decreased employee efficiency and motivation, increased absenteeism rates, increased failure rates in selecting the best people for the job, diminished competitive advantage and as a result of these, decreased overall efficiency and effectiveness of the organization.

\begin{abstract}
Although there are legal regulations concerning workforce discrimination, discriminatory practices continue to exist. On the other hand, changing world of today and globalization result in more organizations valuing workforce diversity. Diversity means that organizations are becoming more heterogeneous in terms of sex, race, age, national origin, thought, viewpoint etc.
\end{abstract}

\section{HUMAN CAPITAL HETEROGENEITY}

Heterogeneity stands for organizational or societal variety in which human beings differ from one another demographically (Ferris, Buckley \& Fedor, 2002:122). The variety of workforce concept consists of several dimensions which can be named as gender, race, nationality, religion and disability (Byars \&Rue, 2000:7). Heterogeneity in human capital stands for human features that diverge individuals from one another. (Mejia, Balkin \& Cardy, 2001:124).

The dimensions of variety can be categorized under two frameworks. The primary dimension consists of basic features which every individual has in common and features that can not be changed (Reece \& Brandt, 2003:156); they are born and/or specify the features that start in early socialization process of individuals which have an important impact on life-long period of every individual. The primary dimensions are age, ethical background, gender, physical and mental abilities, race and sexual preferences (Loden \& Rosener, 1991:18-19, Reece \& Brandt, 2003:156). The secondary dimensions consist of features that individuals can change consciously and on purpose, can gain or can quit, such as education level, residential location, marital status, work experience, 
income level, religious beliefs, political beliefs, health habits, communication means (Mejia, Balkin \& Cardy, 2001:124, Reece \& Brandt, 2003:156).

\section{III.THE REASONS OF HUMAN CAPITAL HETEROGEONITY}

In the new era, globalization and its' recently formed structural consequences have led Human Capital Heterogeneity $(\mathrm{HCH})$ to become an important issue. Especially, $\mathrm{HCH}$ in the organizational systems should be designed in order to support the expansion to different markets, and to establish a synergic organizational culture.

There are numberless developments that led "Change is good" mentality rather than "Change is bad" mentality to take over in organizational change process. These developments can be summarized as;

Structure

\section{a. Change in Workforce Demographic}

The change in workforce demographic structure has changed the size and the composition of new employees pool (DeNisi \& Griffin, 2001:477).

\section{b. Globalization of Market}

Global variety means everything and everyone should be analyzed in concept of resemblance and diversification features (Byars ve Rue; 2000:8).

c. Shift from Production Economics to Service Economics

d. Organizational Understanding of Variety and/or Diversification Features

Another important factor for contributing workforce diversification is organizational understanding of workforce quality improvement by employing and promoting the most qualified (DeNisi \&Griffin, 2001:477). e. New Business Strategies that Stimulate Teamwork Necessity

Organizations should be in the position to overcome the broad set targets and goals in order to be more durable, serve better and be successful. Thus, organizations should accomplish strategies that one specific department can not fulfill (Cascio, 2003:124).

\section{IV.RESEARCH METHODOLOGY}

In our era, organizations should speak the cross-cultural language to succeed in the global competitive environment. New diversified communication tools that respond to various demands and needs should be developed and supply of similar product policies should be departed (Loden \& Rosener, 1991:10).

One of the basic factors that organizations need to be successful, is to divert workforce and segment customer variety. Organizations that differ in terms of culture, language, clothing, customs and traditions that fulfill the necessity of being parallel to customers, respond their needs and requirements in a fast and convenient way.

In this study, service sector in which $\mathrm{HCH}$ term counts most, has been preferred. The conduct of study is planned to be in hotels area because of customer variety it offers and 24/7 service mentality, employment of diversified workforce, possession of various departments. The questionnaire has been developed under this framework and four and five stars hotels in Ankara regions that offer high numbers in terms of employees and low turnover rates, have been chosen as sample. 10 hotels out of 40 hotels have been chosen as sample.

In the questionnaire, demographical variety measurement data is being asked. Dependent on the literature review and primary and/or secondary dimensions, questions of the 
questionnaire are developed. The context contains gender, age, marital status, education level, work period in the job, position in the job, income level, religion, race, ethnical background and the physical or mental abilities. The return rate in 10 hotels is 210 respondents out of 550 employees.

\section{FINDINGS RELATED TO HUMAN CAPITAL HETEROGENEITY}

Two different measurement methods are applied in terms of workforce diversification measurement; Heterogeneity Index of Blau and Coefficient of Variation. Blau gathers parameters in two groups; nominal parameters and graduated parameters. As can be drawn from Figure 1, Blau states that the first parameter indicates heterogeneity and second parameter indicates inequality

(Blau, 1977:8-9). Nominal parameters are the parameters that sub-group the population. Graduated parameters are the parameters that diversify the individuals according to their status ranking (Blau, 1977:7).

Therefore, when measuring demographic diversification, gender, marital status, religion, race, nationality, ethnical background and physical and mental abilities, Blau's Heterogeneity Index is used (Knight, Pearce, Smith, Olian, Sims, Smith \& Flood, 1999:452; Carpenter, 2002:279; Simons, Pelled, Smith, 1999: 666; Carpenter \&Fredrickson, 2001: 538). Coefficient of Variation is used in the measurement of other factors. Data measured with Blau Index.

Measurement using Blau Index depends on the formula indicated below:

(Blau, 1977: 9).

$$
1-\frac{\sum x_{i}^{2}}{\left(\sum x_{i}\right)^{2}}
$$

Data measured with Coefficient of Variation (Standard Deviation and Mean):

Data gathered from hotels are transferred to SPSS program and after having run the program, $\mathrm{SD}$ and Mean values of parameters such as age, education level, position in job, income level parameters are measured together with Blau Index.

\section{HUMAN CAPITAL HETEROGENEITY MEASUREMENT CRITERIA}

According to Blau's Heterogeneity Index, if the whole population is gathered under one group then there is no heterogeneity and the value is equal to zero (0). If all groups are in equal size, heterogeneity approaches to the value one (1) (Blau, 1977:9), which means that heterogeneity is at maximum. Thus;

As Human Capital Heterogeneity approaches to zero, population homogeneity should be pronounced. Workforce diversity is at its' maximum as the population groups show an equal distribution. As to Blau Index, the maximum heterogeneity level depends on the number of groups the population is distributed. When the Index is shown as : $\quad 1-\sum p_{i}^{2}$ ( where " " shows the number of individuals in each group and the percentage of population (Blau, 1977:78), the maximum diversity level for each parameter can be calculated.

In the first half of the study which measures the demographic structural diversity, the parameters such as gender, nationality and physical and mental abilities that are measured with Blau Index, the population is categorized in two groups and the maximum diversification level is 0,50 . Parameters such as religion and ethnical background categorize the population into four categories and the maximum diversification level is 0,75 . Marrital status parameter categorizes the 
population into three groups and the maximum diversification level is 0,667 .

At this stage of the study, Performance Index that concerns finance, sales performance and management systems efficiency of companies has been developed. Under this framework, Performance Indexes of each hotel have been developed by using three factors. The overlapping of Human Capital Heterogeneity and organizational performance is provided in Figure 1.

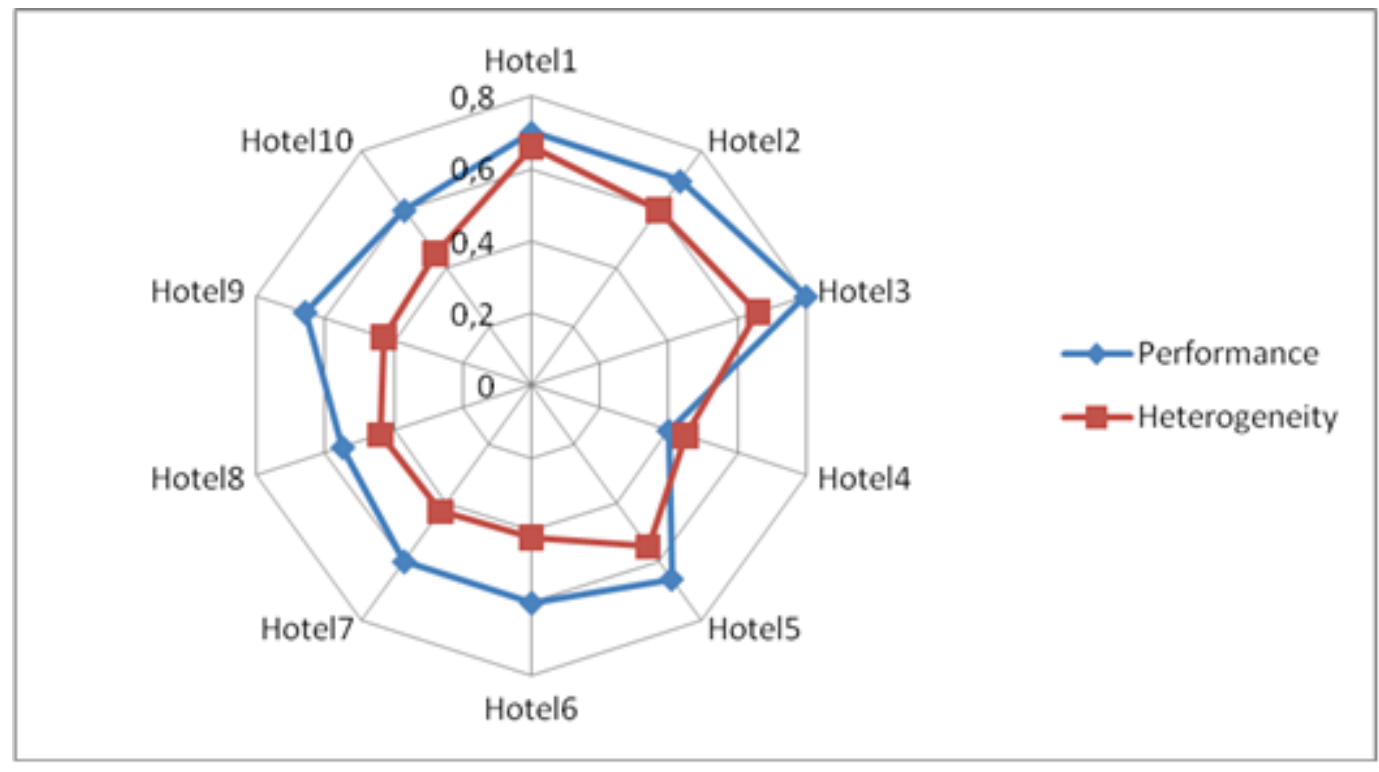

Figure 1: Overlapping of Human Capital Heterogeneity and Organizational Performance of Hotels

As can be drawn fro Figure 1, $\mathrm{HCH}$ of companies creates a synergic effect and allows the company to show a more dynamic and a more innovative approach. Thus, companies should give great attention to plan their human capital stocks and organize them strategically. The companies can maximize their resources in this way and gain competitive advantage.

\section{RESULTS}

The study shows that hotels are neither aware of Human Capital Heterogeneity benefits nor know how to manage the process. They have a broader approach by not employing a diversified workforce in means of nationality diversification. The perception verifies for Turkish nationalities as well as foreign nationalities. The different treatment to Turkish nationalities is perceived as discrimination by foreign nationalities and also different treatment to foreign nationalities is perceived as discrimination by Turkish nationalities. The reason for discrimination perception is cultural differences.

In hotels sector, the customer diversification is a fact due to different customer profiles. The increase in $\mathrm{HCH}$ is a urge to serve cross-cultural customers in better ways as a result of global world economics which lead to foreign subsidiary openings and/or establish strategic alliances. The managers of hotels that serve different nationalities should give importance to this issue and find strategies to avoid such perceptions.

In the correlation analysis, by $\% 95$ meaning, the relation between education level and income level is measured and the result was 0,887 positive correlated. The income level increases as 
the education level increases and visa versa, the education level increases as the income level increases. As the income level increases individuals have more opportunities for a better education and as the education level increases their approach differs. The variation and diversity in approaches lead individuals to think about various behaviors.

The results compared to other studied conducted in the filed, lead to similar results in terms of position in the job, but different in terms of education level. The main result for this difference is the implementation of study conducted in various cultures and in different sectors.

When the job advertisements in Turkey are analyzed, it reveals the fact that individuals who belong to middle-old aged groups are disadvantaged due to fact that job advertisements require age restrictions, innovative thinking and openness to change criteria. During evaluation of job applications, younger applicants are preferred and education opportunities are provided to younger employees.

The result of the study reveals that Human Capital Heterogeneity is low. Dependent on high ranking of Power Distance Index of Hofstede for Turkey and the tendency to avoid conflicts, employers tend not to react against discrimination or accept the inequalities in work environment. As a result of Power Distance Index, employees expect their managers to have an authoritarian management style and be stronger than themselves.

Workforce diversity, besides its' positive features, also possesses negative consequences. The most important consequence is conflict in the organizations, and as a result of grouping of similar employees, the division of communication networks and not being able to profit from different approaches in the organization.
Individuals are complicated systems and each dimension of diversification adds new complicated factor to the system process. Many individuals prefer homogeneity to heterogeneity, known to unknown and being with similar individuals to themselves. The reason for such a tendency is that individuals feel more comfortable and conflicts are minimized (Loden \& Rosener, 1991:23).

It is natural that Human Capital Heterogeneity level is low when the effect of Uncertainty Avoidance Index, avoidance of conflicts, and friendship relations on Turkish culture are analyzed. Whereas, the study is conducted in hotels, thus in service sector. In service sector, customer diversity is high and with respect to this fact, the problem diversity which various personalities' differing needs and requirements result is also high. The problems in service sector, because of existence of human factor, are not always routine. Teamwork, different approaches, innovation and quick response to problems are required. This can only be reached through diversified workforce.

As a result of low Human Capital Heterogeneity in the study, it is seen that in Ankara four and five star hotels still lack such factors, avoid conflicts and are not well informed about conflict resolution techniques. Besides, because of homogenous workforce, services provided will also be limited in terms of variety and this will result in limited customer variety. This result will minimize organization's success and competitive advantage in the globalization process.

For future research, the effect of low ranking Human Capital Heterogeneity on process and the most effective management style to overcome the problems occurred due to this low ranking can be analyzed. 


\section{VIIII. References}

1. ANTHONY, William P., K. M. KACMER \& P. L. PERREWE, 2002 Human Resource Management A Strategic Approach, South-Western / Thomson Learning, 4th Edition, USA.

2. BARUCH, Yehuda, 2003 Managing Careers Theory and Practice, Prentice Hall, England.

3. BLACKABY, David, L. H. PELLED ve K. A. SMITH, 1999 "Making Use of Difference: Diversity, Debate, and Decision Comprehensiveness in Top Management Teams”, Academy of Management Journal, vol. 42, no. 6, 662-673.

4. BLAU, Peter M., 1977 Inequality and Heterogeneity, Collier Macmillan, USA.

5. BRADY, Teresa, 1996 "The Downside of Diversity", Management Review.

6. BYARS, Lloyd L. \& L. W. RUE, 2000, Human Resource Management, McGraw-Hill, 6th Edition, USA.

7. CARPENTER, Mason A., 2002 "The Implications of Strategy and Social Context for The Relationship Between Top Management Team Heterogeneity and Firm Performance”, Strategic Management Journal, 23, $275-284$

8. CARPENTER, Mason A. J. W. FREDRICKSON, 2001 "Top Management Teams, Global Strategic Posture, and The Moderating Role of Uncertainty”, Academy of Management Journal, vol. 44, no. 3, 533-545.

9. CARRELL, Michael R., N. F. ELBERT \&R. D. HATFIELD, 2000 Human Resource Management Strategies for Managing a Diverse and Global Workforce, The Dryden Press,6th Edition, USA.

10. CASCIO, Wayne F., 2003, Managing Human Resources Productivity, Quality of Work Life, Profits, McGraw-Hill, 6th Edition, USA.

11. ÇAĞLAR, İrfan, 2001, "Yönetim-Kültür Bağlamında Türk Yönetim Modelinin Saptanmasına Yönelik Kavramsal Bir Çalışma", G.Ü.İ.İ.B.F. Dergisi, 3, 125-148.

12. DeNISI, Angelo S. \& R. W. GRIFFIN, 2001 Human Resource Management, Houghton Mifflin Company, USA.

13. FERRIS, Gerald R., M. R. BUCKLEY \& D. B. FEDOR, 2002 Human Resource Management Perspectives, Context, Functions and Outcomes, Prentice Hall, 4th Edition, USA.

14. HULTIN, Mia, 1998, "Gender Differences in Workplace Authority: Discrimination and the Role of Organizational Leaders", ACTA Sociologica, vol.41.

15. KIRCHMEYER, Catherine, 2002 “Gender Differences in Managerial Careers: Yesterday, Today and Tomorrow", Journal of Business Ethics, 37, 5-24. 
16. KNIGHT, Don, 1999 “Top Management Team Diversity, Group Process, and Strategic Consensus”, Strategic Management Journal, 20, 445-465.

17. KOÇEL, Tamer, 2003 İşletme Yöneticiliği, Beta Basım A.Ş., 9. Baskı, İSTANBUL.

18. MATHIS, Robert L. ve J.H. JACKSON, 1994 Human Resource Management, West Publishing Corporation, 7th Edition, USA.

19. MATHIS, Robert L. ve J. H. JACKSON, 2000 Human Resource Management, South-Western, 9th Edition, USA.

20. MATHIS, Robert L. \& J.H. JACKSON, 2005 Human Resource Management Essential Perspectives, Thomson South- Western, 3rd Edition, Canada.

21. REECE, Barry L.\&R. BRANDT, 2003 Human Relations Principles and Practices, Houghton Mifflin Company, 5th Edition, USA.

22. ROBBINS, Stephan P., 2003 Essentials of Organizational Behavior, Prentice Hall, 7th Edition, USA.

23. SIMONS, Tony, L. H. PELLED \& K. A. SMITH, 1999 "Making Use of Difference: Diversity, Debate, and Decision Comprehensiveness in Top Management Teams", Academy of Management Journal, vol. 42, no. 6, $662-673$. 